\title{
Study on Passive Earth Pressure of Retaining Wall in Transversely Isotropic Soil
}

\author{
Tao Chen ${ }^{1}$, Chao Chen ${ }^{1}$, Fengting Guan ${ }^{2}$, and Ruoyang Zhou ${ }^{1}$ \\ ${ }^{1}$ School of Civil and Transportation Engineering, Guangdong University of Technology, Guangzhou 510006, Guangdong, China \\ ${ }^{2}$ Guangdong University of Foreign Studies, College of Education, Guangzhou 510006, Guangdong, China
}

\begin{abstract}
Based on the fabric tensor theory and the principle of least square method, the method of block processing in the same model to explore the variation of the passive earth pressure of the transversely isotropic soil was used in the study. At the same time, primary displacement application and multiple displacement application were applied to change the angle between the large principal stress direction of the filling and the normal direction of the deposition surface to obtain the new strength parameters $c i$ and $\varphi i$ of each block after the model was divided and additionally analyzing the variation of the anisotropic passive earth pressure. The study shows: 1.Considering the transverse isotropy of the soil and reaching the limit equilibrium, the passive earth pressure of the soil after multiple displacement application is not only smaller than that after primary displacement application but also closed to the theoretical solution of Coulomb's earth pressure; 2.When the soil is inclined, the anisotropy is significant when compared with the horizontal direction.
\end{abstract}

\section{Introction}

At present, the two classical theories of Rankine and Coulomb pressure are still widely used to calculate the earth pressure $^{[1]}$. However, he earth pressure distribution curves obtained by the two classical calculation methods are not in accordance with the actual conditions. Tsagareli ${ }^{[2]}$ Fang $^{[3]}$ and others have proved through a large number of experiments that the earth pressure behind the retaining wall is curved.

With the development of science and technology, many scholars use finite element software to study earth pressure. Chen Yekai ${ }^{[4]}$ et al. used an elastoplastic model for soil, and discussed the earth pressure under different displacement modes. It is concluded that the nonlinear distribution of earth pressure behind the wall acts on the retaining wall as a process of gradual yielding and only reaches the limit state when the soil behind the wall forms a penetrating plastic zone. Li Xiumei ${ }^{[5]}$ used discrete elements to simulate the earth pressure of the retaining wall and found that the earth pressure distribution is related to the displacement mode.

Although the above studies have revised and expanded the two classical theories, it is still assumed that the filling is discussed under isotropic materials. However, in the normally consolidated natural soil layer, some major principal stresses are vertical. Therefore, the arrangement of the particle long axes tends to be horizontal. At this time, the intrinsic anisotropy of clay is transversely isotropic, and the vertical axis is its symmetry axis. That is to say, the physical and mechanical properties of clay on a horizontal plane are isotropic, and the properties on any plane will vary with the angle between the plane and the horizontal plane ${ }^{[6]}$.

From micro angle, translational displacement mode are considered to cause the major principal stress direction of the soil behind the wall and the normal direction of the deposition surface deflected ${ }^{[7,8]}$, resulting in the change of soil strength parameters $c$ and $\varphi$. In addition, other kinds of factors which influence the passive earth pressure are also in consideration.

\section{Finite Element Calculation Model for Earth Pressure of Retaining Wall}

\subsection{Geometric Model}

The calculation of earth pressure of gravity retaining wall is taken as a plane problem, and ABAQUS finite element analysis software is used. Retaining wall to take concrete material, the wall height is $\mathrm{H}=5.0 \mathrm{~m}$, the top width is $1 \mathrm{~m}$, the bottom width is $3 \mathrm{~m}$, and the back of the retaining wall is vertical and smooth. The horizontal length of the soil behind the wall is taken as $4 \mathrm{H}$.The foundation is a hard foundation, and we consider that foundation has little effect on the earth pressure of the retaining wall. Thus, take the thickness of the foundation the same as the wall height for $28 \mathrm{~m}$ thick. The retaining wall, the soil and foundation are all equipped with a 4-node planar strain cell CPE4. The top of the wall and the airborne node are free, and the soils at the left and right ends and foundation boundary node are 
horizontally constrained and vertically oriented; the boundary nodes of the foundation bottom are horizontally and vertically constrained ${ }^{[9]}$.

\subsection{Mechanical Parameters}

Gravity concrete retaining wall has few steel bars and the stress is small, thus it is considered as the elastic material. The weight of retaining wall is $25 \mathrm{kN} / \mathrm{m}^{3}$ and the elastic modulus is $2.5 \times 105 \mathrm{MPa}$, Poisson's ratio $\mu=0.16$; the foundation is taken as elasticity whose elastic modulus is $3 \times 103 \mathrm{MPa}$; The soil is made of cohesive soil, and the Mohr-coulomb model is selected; the unrelated flow rule is used to calculate; take the soil weight of $18 \mathrm{kN} / \mathrm{m}^{3}$; the friction unit between the retaining wall and the foundation is 0.22 ; the soil and the foundation are in contact with the tie, and the retaining wall and soil are in smooth contact.

\subsection{Soil Parameter Determination}

The soil parameters were selected by Kurukulasuriya ${ }^{[10]}$ et al. Cut out ceramic clay sample with different inclination angles from the normal to the deposition surface. The effective shear strength obtained through experiments is shown in Table 1. The model is shown in Figure 1:

Tab.1 Effective shear strength parameters

\begin{tabular}{ccccc}
\hline$\alpha /\left(^{\circ}\right)$ & 0 & 30 & 60 & 90 \\
\hline $\mathrm{c}^{\prime} /(\mathrm{kPa})$ & 10.1 & 8.9 & 6.3 & 9.0 \\
$\varphi^{\prime} /\left(^{\circ}\right)$ & 25.3 & 24 & 23.5 & 27.2 \\
\hline & & & & \\
& & & & \\
\end{tabular}

Figure 1 Stress diagram of retaining wall model

The new intensity parameters $c_{i}$ and $\varphi_{i}$ of the angle between the major principal stress directions and the normal direction of the deposition surface can be obtained.

$$
\begin{array}{r}
\mathrm{c}_{\mathrm{i}}=6.245 \cdot\left(1+\mathrm{A}_{\mathrm{c}}+81.607 \mathrm{~A}_{\mathrm{c}}^{2}-408.861 \mathrm{~A}_{\mathrm{c}}^{3}\right) \\
\left.\varphi_{\mathrm{i}}=\arctan \left[0.466 \cdot\left(1+\mathrm{A}_{\varphi}+3.748 \mathrm{~A}_{\varphi}^{2}-15.606 \mathrm{~A}_{\varphi}^{3}\right)\right]\right] \\
A_{\varphi}=0.0845\left(1-3 \cos ^{2} \alpha\right) \\
A_{c}=-0.0682\left(1-3 \cos ^{2} \alpha\right)
\end{array}
$$

It can be calculated that when the highest power is equal to 3 , the fitting effect is exactly the same.

\section{Finite Element Analysis of Earth Pressure on Retaining Wall of Transversely Isotropic Soil}

Considering the finite element method for earth pressure analysis of retaining wall under strength anisotropy, change of stress field of the soil is needed to calculate after force. For the plane strain problem, the direction angle of the large principal stress of a unit can be determined by the following formula ${ }^{[11]}$ :

$\cos 2 \alpha=\frac{\left(\sigma_{y}-\sigma_{x}\right)}{2 r}, r=\sqrt{\frac{\left(\sigma_{y}-\sigma_{x}\right)^{2}}{4}+\tau_{x y}^{2}}$

,in the formula $\sigma_{x}$ and $\sigma_{y}$ represent the horizontal normal stress, vertical normal stress and shear stress of the element in the xy plane; $r$ represent the radius of stress Mohr.

\subsection{Isotropy}

Take $\alpha=0^{\circ}$ (horizontal deposition surface), shear strength parameters $c=10.1 \mathrm{kPa}, \varphi=25.3^{\circ}$ as the soil strength isotropic parameters. Through the ABAQUS finite element calculation and the determination of rupture state, it can be known when the wall is smooth, the horizontal displacement is $0.2 \mathrm{~m}$ (displacement ratio is $4 \%$ ). In this case, the soil reaches the passive rupture limit and the total passive earth pressure is $1817.949 \mathrm{kN} / \mathrm{m}$. When the wall is rough, the horizontal displacement is $0.25 \mathrm{~m}$ (displacement ratio $5 \%$ ) and the total passive earth pressure is $2468.389 \mathrm{kN} / \mathrm{m}$.

\subsection{One displacement}

Apply the horizontal displacement of the retaining wall to $0.2 \mathrm{~m}$ (the wall displacement ratio is $4 \%$ ), since it is discussed under the transverse isotropic nature of the soil, the shear strength parameters $c=10.1 \mathrm{kPa}$ and $\varphi=$ $25.3^{\circ}$ when $\alpha=0^{\circ} \quad$ (the level of the deposition surface) are selected. The ABAQUS can be used to calculate the stress and strain distribution of the soil after the displacement is applied as shown in Fig. 2 3.

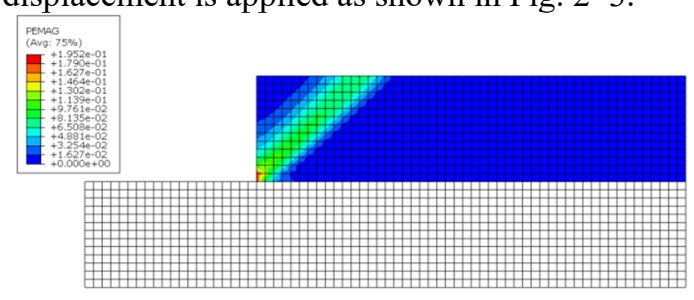

Fig.2 Plastic Distribution of 4\% Displacement Ratio

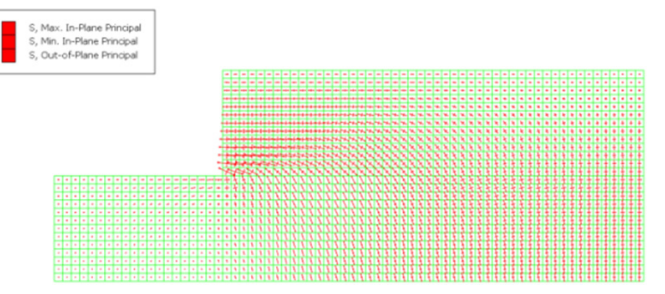

Fig.3 Stress vector with a displacement ratio of $4 \%$

The law of the soil stress distribution obtained from Figure 5 is as follows: For the soil closer to the boundary area of the retaining wall, the large principal stress direction deflection angle $\alpha$ is larger and close to $90^{\circ}$ behind the wall, and the deflection of the large principal stress direction $\alpha$ away from the retaining wall is smaller. According to the above rules and using the angle of each 
soil grid unit calculated in excel, the model shown in Fig. 1 is processed in blocks and utilizing the average value of the $\alpha$ angle of each block and the degree of anisotropy of the equation (2) in different $\alpha$ ranges, the shear strength parameters $c_{i}$ and $\varphi_{i}$ of the soil in each block can be obtained. Figure 4 shows the retaining wall model after the block processing, and table 2 shows the adjusted strength parameters of each block.

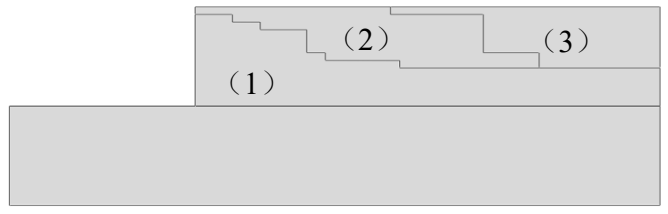

Fig.4 Image after dividing the block

Tab. 2 Strength parameters adjusted for each block

\begin{tabular}{llll}
\hline $\begin{array}{l}\text { Clay } \\
\text { number }\end{array}$ & $\begin{array}{l}\text { Average } \\
\text { angle } \alpha /\left(^{\circ}\right)\end{array}$ & $\begin{array}{l}\text { Cohesion } \\
c /(\mathrm{kPa})\end{array}$ & $\begin{array}{l}\text { Internal } \\
\text { friction } \\
\text { angle } \varphi /\left(^{\circ}\right)\end{array}$ \\
\hline$(1)$ & 88.44 & 9.0 & 27.1 \\
$(2)$ & 52.87 & 6.3 & 22.9 \\
$(3)$ & 14.4 & 10 & 25.2 \\
\hline
\end{tabular}

At this time, in the ABAQUS software, the model after the block processing in Fig. 4 is applied, and the displacement of $0.18 \mathrm{~m}$ (the displacement ratio is $3.6 \%$ ) can be used to obtain the passive earth pressure after the displacement is applied once.

\subsection{Multiple displacement application}

Apply the horizontal displacement of the retaining wall to the model in three steps, after the displacement is completed in the first step, the strength parameters caused by the change of the principal stress direction of each unit in the equilibrium state change. After dividing the block according to the above division principle, the model after the block is obtained and the corresponding new intensity parameters $c_{\mathrm{i}} 、 \varphi_{\mathrm{i}}$ are brought in, and the next displacement is applied. Repeat the above process until all three displacements have been completed.

After several trials using ABAQUS, the first applied displacement value is $0.02 \mathrm{~m}$ (wall displacement ratio is $4 \%$ ), and the soil begins to produce less plastic strain and the stress-strain distribution is shown in Figures 5.

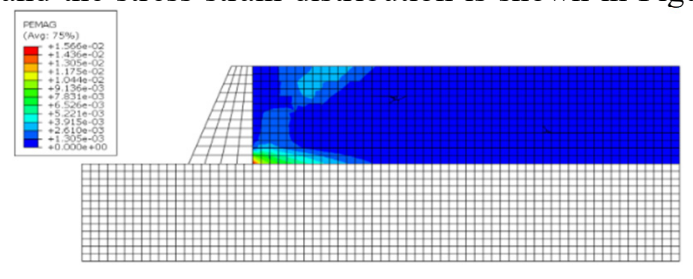

Fig.5 Plastic Distribution

The model shown in Figure 1 is divided into blocks, and the grid unit is divided into blocks as shown in Figure 6:

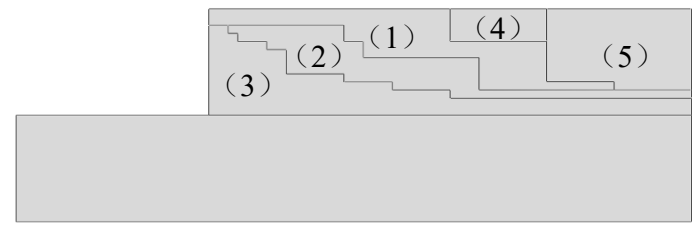

Fig.6 Image after dividing the block

Tab. 3 Parameters after partitioning

\begin{tabular}{llll}
\hline $\begin{array}{l}\text { Clay } \\
\text { number }\end{array}$ & $\begin{array}{l}\text { Average } \\
\text { angle } \alpha /\left(^{\circ}\right)\end{array}$ & $\begin{array}{l}\text { Cohesion } \\
c /(\mathrm{kPa})\end{array}$ & $\begin{array}{l}\text { Internal } \\
\text { friction } \\
\text { angle } \varphi /\left(^{\circ}\right)\end{array}$ \\
\hline$(1)$ & 87.7 & 9.0 & 27.1 \\
$(2)$ & 40.6 & 7.5 & 23.1 \\
$(3)$ & 67.3 & 6.9 & 24.5 \\
$(4)$ & 17.9 & 9.9 & 25.0 \\
$(5)$ & 8.5 & 10.1 & 25.3 \\
\hline
\end{tabular}

Applying the second step displacement value is $0.08 \mathrm{~m}$ (displacement ratio is $1.6 \%$ ). The simulation results are shown in Figures 7:

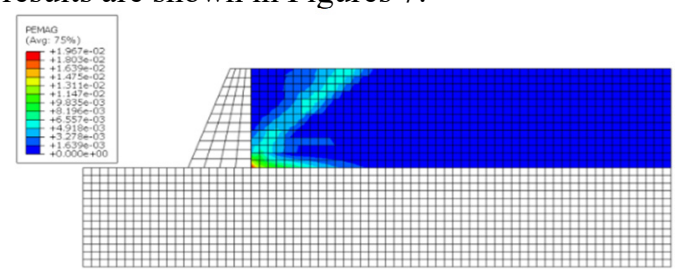

Fig.7 Plastic Distribution

According to the first blocking principle, the large principal stress direction angle of each soil grid unit calculated and using excel can be used. Blocking the model shown, after the first displacement is applied, the stress inside the soil has become disordered. At this time, the stress vector diagram in ABAQUS can only provide a general trend of stress distribution. The specific block is mainly to view the large principal stress deflection angle value of each grid unit of the soil calculated in excel, the block results are shown in Figure 8:

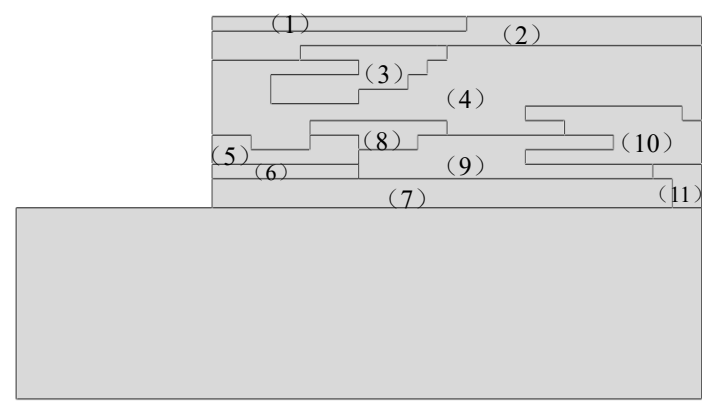

Fig.8 Image after dividing the block 
Tab.6 Parameters after partitioning

\begin{tabular}{cccc}
\hline $\begin{array}{l}\text { Clay } \\
\text { number }\end{array}$ & $\begin{array}{l}\text { Average } \\
\text { angle } \alpha /\left(^{\circ}\right)\end{array}$ & $\begin{array}{l}\text { Cohesion } \\
c /(\mathrm{kPa})\end{array}$ & $\begin{array}{l}\text { Internal } \\
\text { friction } \\
\text { angle } \varphi /\left(^{\circ}\right)\end{array}$ \\
\hline$(1)$ & 79.8 & 8.4 & 26.5 \\
$(2)$ & 12.7 & 10.0 & 25.2 \\
$(3)$ & 38.1 & 7.8 & 23.3 \\
$(4)$ & 78.8 & 8.3 & 26.3 \\
$(5)$ & 59.0 & 6.3 & 23.3 \\
$(6)$ & 29.0 & 9.0 & 24.1 \\
$(7)$ & 84.7 & 8.8 & 26.9 \\
$(8)$ & 13.0 & 10.0 & 25.2 \\
$(9)$ & 53.1 & 6.3 & 22.9 \\
$(10)$ & 12.6 & 10.0 & 25.2 \\
$(11)$ & 70.6 & 7.3 & 25.0 \\
\hline
\end{tabular}

Applying a third step displacement value of $0.12 \mathrm{~m}$ (displacement ratio of $2.4 \%$ ), the block results are shown in Figure 9 and the parameters are shown in Table 7.

Tab. 7 Parameters after partitioning

\begin{tabular}{lcll}
\hline $\begin{array}{l}\text { Clay } \\
\text { number }\end{array}$ & $\begin{array}{c}\text { Average } \\
\text { angle } \alpha /\left({ }^{\circ}\right)\end{array}$ & $\begin{array}{c}\text { Cohesion } \\
c /(\mathrm{kPa})\end{array}$ & $\begin{array}{l}\text { Internal } \\
\text { friction } \\
\text { angle } \varphi /\left({ }^{\circ}\right)\end{array}$ \\
\hline$(1)$ & 62.3 & 6.4 & 23.7 \\
$(2)$ & 84.4 & 8.8 & 26.9 \\
$(3)$ & 2.6 & 10.1 & 25.4 \\
$(4)$ & 60.4 & 6.3 & 23.5 \\
$(5)$ & 24.4 & 9.5 & 24.5 \\
$(6)$ & 87.2 & 8.9 & 27.0 \\
$(7)$ & 9.4 & 10.0 & 25.3 \\
$(8)$ & 55.9 & 6.2 & 23.0 \\
$(9)$ & 17.0 & 9.9 & 25.0 \\
$(10)$ & 42.6 & 7.2 & 23.0 \\
$(11)$ & 87.3 & 8.9 & 27.0 \\
$(12)$ & 48.9 & 6.6 & 22.8 \\
$(13)$ & 61.9 & 6.4 & 23.7 \\
$(14)$ & 72.9 & 7.6 & 25.4 \\
$(15)$ & 25.0 & 9.4 & 24.5 \\
$(16)$ & 3.0 & 10.1 & 25.4 \\
$(17)$ & 39.3 & 7.7 & 23.2 \\
$(18)$ & 65.2 & 6.7 & 24.2 \\
$(19)$ & 10.1 & 10.0 & 25.3 \\
$(20)$ & 17.8 & 9.9 & 25.0 \\
$(21)$ & 65.6 & 6.7 & 24.2 \\
\hline
\end{tabular}

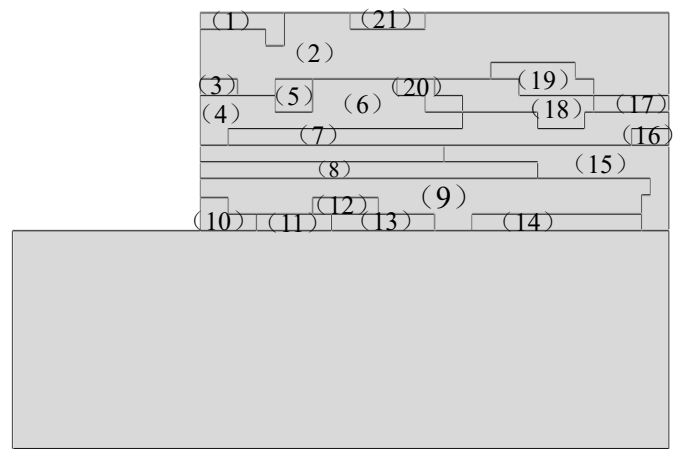

Fig.9 Image after dividing the block

According to the determination of the damage, the displacement of the soil reaching the ultimate failure state after the three displacements is applied is $0.14 \mathrm{~m}$ (the displacement ratio is $2.8 \%$ )

\subsection{Summary}

This section is based on considering the transverse isotropic nature of the soil, calculate the passive earth pressure after one application of displacement and three times of displacement, and the opposite of the results of isotropic is shown in Table 8:

\begin{tabular}{cccl}
\hline category & $\begin{array}{c}\text { Isotropic } \\
/(\mathrm{kN} / \mathrm{m})\end{array}$ & $\begin{array}{l}\text { Anisotropy/ } \\
(\mathrm{kN} / \mathrm{m})\end{array}$ & $\begin{array}{l}\text { Relative } \\
\text { rate of } \\
\text { change } \\
(\%)\end{array}$ \\
\hline $\begin{array}{c}\text { One } \\
\text { displacement } \\
\text { Multiple } \\
\text { displacement }\end{array}$ & 1817.949 & 1775.812 & 2.3 \\
\hline
\end{tabular}

Tab.8 Comparison of isotropic and anisotropic

Rankine soil pressure:

$$
\begin{array}{r}
\mathrm{E}_{\mathrm{p}}=\frac{1}{2} \gamma H^{2} \mathrm{~K}_{\mathrm{P}}+2 \mathrm{cH} \sqrt{\mathrm{K}_{\mathrm{P}}} \approx 720 \mathrm{kPa} \\
\text { and } K_{\mathrm{p}}=\tan ^{2}\left(45^{\circ}+\varphi / 2\right) .
\end{array}
$$

Coulomb pressure:

$$
\begin{aligned}
& \mathrm{E}_{\mathrm{p}}=\frac{1}{2} \gamma \mathrm{H}^{2} \mathrm{~K}_{\mathrm{P}} \approx 1470 \mathrm{kPa} \\
& \text { and } \\
& \mathrm{K}_{\mathrm{p}}=\frac{\cos ^{2}(\varphi+\alpha)}{\cos ^{2} \alpha \cos (\alpha-\delta)\left[1-\sqrt{\frac{\sin (\varphi+\delta) \sin (\varphi+\beta)}{\cos (\alpha-\delta) \cos (\alpha-\beta)}}\right]^{2}}
\end{aligned}
$$

Compare the results with Rankine's earth pressure and Coulomb's soil pressure, it can be concluded that the theoretical solution of Rankine is much smaller than the numerical solution, and coulomb's theoretical solution is similar to the anisotropic solution after multiple displacements, this is because the Rankine earth pressure theory makes many assumptions that ignore the friction but the Coulomb earth pressure theory is 
closer to the actual limit passive earth pressure. $\mathrm{Xu}$ Riqing $^{[12]}$ and others in the rigid retaining wall model test to obtain the same conclusion of passive earth pressure in $\mathrm{T}$ mode. The three situations are summarized as shown in Figure 13 below. The earth pressure is close to the straight line along the back of the wall, The pressure value decreases near the wall, similar to the earth pressure curve studied by Zhao Guanghui ${ }^{[13]}$, the reason is that the soil pressure at the bottom of the wall is reduced by the friction of the bottom soil.

\section{Soil slope on the significant influence of anisotropy}

Use $\alpha=30^{\circ}$ (That is, the deposition surface is $30^{\circ}$ from the horizontal plane), Similar to the previous section IV, the model displacement can be calculated once by ABAQUS (According to the state of damage, the wall displacement ratio is $3 \%$ ). The model after the soil reaches the passive limit state is shown in Figure 14; Table 9 shows the parameters after the block.

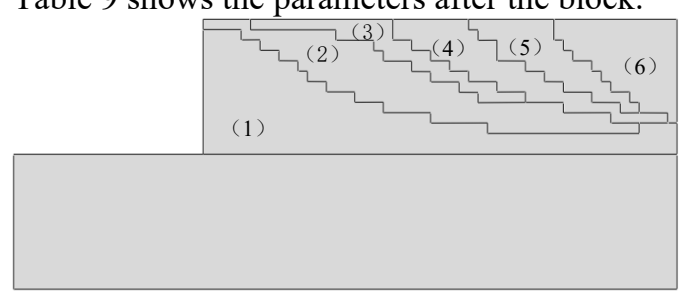

Fig.14 Image after dividing the block

Tab. 9 Parameters after partitioning

\begin{tabular}{llcc}
\hline $\begin{array}{l}\text { Clay } \\
\text { number }\end{array}$ & $\begin{array}{l}\text { Average } \\
\text { angle } \\
\alpha /\left(^{\circ}\right)\end{array}$ & $\begin{array}{l}\text { Cohesion } \\
c /(\mathrm{kPa})\end{array}$ & $\begin{array}{l}\text { Internal } \\
\text { friction } \\
\text { angle } \varphi /\left(^{\circ}\right)\end{array}$ \\
\hline$(1)$ & 57.8 & 6.2 & 23.2 \\
$(2)$ & 36.2 & 8.1 & 23.5 \\
$(3)$ & 15.7 & 10.0 & 25.1 \\
$(4)$ & 0.4 & 10.1 & 25.3 \\
$(5)$ & 14.3 & 9.9 & 25.2 \\
$(6)$ & 24.7 & 9.4 & 24.5 \\
\hline
\end{tabular}

The displacement ratio reaching the limit state at this time is $2 \%$.

Tab.8 Comparison between soil tilt and soil horizontal

\begin{tabular}{lrrc}
\hline $\begin{array}{l}\text { Average } \\
\text { angle } \\
\alpha /\left(^{\circ}\right)\end{array}$ & $\begin{array}{r}\text { Isotropic } \\
(\mathrm{kN} / \mathrm{m})\end{array}$ & $\begin{array}{r}\text { Anisotrop } \\
\mathrm{y} /(\mathrm{kN} / \mathrm{m})\end{array}$ & $\begin{array}{l}\text { Relative rate of } \\
\text { change } /(\%)\end{array}$ \\
\hline$\alpha=0$ & 1817.949 & 1775.812 & 2.3 \\
$\alpha=30$ & 1817.949 & 1559.145 & 16.6 \\
\hline
\end{tabular}

\section{Conclusion}

In order to pursue a more realistic stress field inside the soil, when the passive earth pressure wall is translated, the same model is applied with primary displacement application and multiple displacement application.

(1) In the transversely isotropic soil, the passive earth pressure of the soil after multiple displacement application is not only smaller than that after primary displacement application but also closed to the theoretical solution of Coulomb's earth pressure with displacements increasing. The rupture surface generated by primary displacement application is a plane, and the rupture surface generated after the multiple displacements application is a curved surface.

(2) When $\alpha=30^{\circ}$, anisotropy ratio is more significant than that when $\alpha=0^{\circ}$. It's because the average principal stress deflection angle of the plastic penetration region at $\alpha=30^{\circ}$ is between $42^{\circ}$ and $57^{\circ}$, and the strength parameter of this region is very small. Thus, in this case the passive earth pressure will be reduced a lot.

\section{References}

1. G W C, Building science (China Building Materials Industry Press, Beijing, 2004).

2. TSAGAELIZ V. Soil. Mech. Found. Eng, 2(4), 197-200,(1965)

3. FANG Y, ISHIBASHI I. Geo. Eng, 120(8), 317-333, (1994)

4. CHEN Y K. Hangzhou: Zhejiang University, 2001.

5. LI $X$ M, JIANG $M$ J. Under. Space. Eng, 6(1):60-64, (2010)

6. TATSUOKA F, SAKAMOTO M, KAWAMURA T, et al. Soils. Found, 26(1), 65-84, (2008)

7. ZENG Q Y, ZHOU J. Rock. Soil. Mech, 2005(S1), 43-47, (2005)

8. CHEN Y K. Rock. Mech. Eng, 2002(8):1275, (2002)

9. LI Y G, ZHOU H Z. Shanxi Water Resources Sci. Tech, 2017(4),1-2+38, (2017)

10. Kurukulasuriya L C,Oda M,Kazama H. Soil. Found, 39(1), 21-29, (1999)

11. WANG D, JIN X. Rock. Soil. Mech, 29(3), 667-672, (2008)

12. XU R Q,CHEN Y K,YANG Z X,GONG X N. Geo. Eng, 2002(5), 569-575, (2002)

13. ZHAO G H. Cryogenics. Tech, 34(6), 129-130, (2012) 